\title{
Hallux valgus deformity and postural sway: a cross-sectional study
}

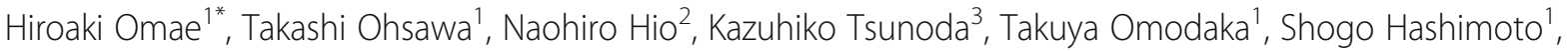
Akira Ueno ${ }^{1}$, Tsuyoshi Tajika', Yoichi lizuka ${ }^{1}$ and Hirotaka Chikuda ${ }^{1}$

\begin{abstract}
Background: Hallux valgus deformity has been reported to be associated with increased postural sway. However, the direction and magnitude of postural sway associated with hallux valgus remain inconclusive. We assessed the association between hallux valgus deformity and postural sway using a force plate.

Methods: The subjects were 169 healthy volunteers, > 40 years old (63 males, 106 females, average age: $66.0 \pm 12.4$ years old), who took part in an annual medical examination. We investigated the photographic hallux valgus angle $\left({ }^{\circ}\right)$, total trajectory length of the gravity center fluctuation $(\mathrm{mm})$, area of the center of pressure $\left(\mathrm{mm}^{2}\right)$, mediolateral and anteroposterior postural sway $(\mathrm{mm})$ in a standing position with 2-legged stance and eyes open, hallux pain (Numerical Rating Scale), trunk and lower limb muscle mass ( $\mathrm{kg})$. We classified the subjects into a hallux valgus group $(n=44$, photographic hallux valgus angle of 1 or both feet $\left.\geq 20^{\circ}\right)$ and a no hallux valgus group $(n=125$, photographic hallux valgus angle of both feet $<20^{\circ}$ ) and analyzed the relationship between hallux valgus and postural sway.

Results: The anteroposterior postural sway in the hallux valgus group $(6.5 \pm 2.8)$ was significantly greater than in the no hallux valgus group (5.4 $\pm 2.2, p=0.014)$, and the lower limb muscle mass in the hallux valgus group (12.4 \pm 2.2$)$ was significantly smaller than in the no hallux valgus group $(13.5 \pm 3.2, p=0.016)$. The total value of the photographic hallux valgus angle on both feet was positively correlated with the anteroposterior postural sway $(p=0.021)$ and negatively correlated with the lower limb muscle mass ( $p=0.038$ ). The presence of hallux valgus $(p=0.024)$ and photographic hallux valgus angle $(p=0.008)$ were independently related to the magnitude of anteroposterior postural sway.
\end{abstract}

Conclusions: Hallux valgus deformity and its severity were positively associated with the magnitude of the anteroposterior postural sway.

Trial registration: 2017 - 135. Registered 22 August 2017.

Keywords: Photographic hallux valgus angle, Anteroposterior postural sway, Force plate

\footnotetext{
* Correspondence: m1820041@gunma-u.ac.jp

'Department of Orthopaedic Surgery, Gunma University Graduate School of

Medicine, 3-39-22, Showa, Gunma 371-8511 Maebashi, Japan

Full list of author information is available at the end of the article
}

(c) The Author(s). 2021 Open Access This article is licensed under a Creative Commons Attribution 4.0 International License, which permits use, sharing, adaptation, distribution and reproduction in any medium or format, as long as you give appropriate credit to the original author(s) and the source, provide a link to the Creative Commons licence, and indicate if changes were made. The images or other third party material in this article are included in the article's Creative Commons licence, unless indicated otherwise in a credit line to the material. If material is not included in the article's Creative Commons licence and your intended use is not permitted by statutory regulation or exceeds the permitted use, you will need to obtain permission directly from the copyright holder. To view a copy of this licence, visit http://creativecommons.org/licenses/by/4.0/. The Creative Commons Public Domain Dedication waiver (http://creativecommons.org/publicdomain/zero/1.0/) applies to the data made available in this article, unless otherwise stated in a credit line to the data. 


\section{Background}

Hallux valgus (HV) is one of the most common foot deformities in adults [1], with a reported prevalence of up to about $30 \%[2,3]$. There have been studies showing that $\mathrm{HV}$ is associated with greater postural sway, and the presence of $\mathrm{HV}$ is assumed to be related to the risk of fall for this reason [4-6]. A study showed that falls from the standing position and with eyes open were associated with not mediolateral postural sway but anteroposterior sway, and the postural sway in fallers was $25 \%$ greater than that in non-fallers [7]. However, the direction and magnitude of postural sway associated with the presence or severity of HV remain inconclusive. Furthermore, previous studies have suggested that muscle mass is a potential confounder of the HV status and postural sway [8-13].

The present study clarified the relationship between the direction and magnitude of postural sway and the presence or severity of $\mathrm{HV}$ using a multivariate analysis adjusted for potential confounders, including muscle mass.

\section{Materials and methods \\ Subjects}

In a mountain village (Katashina Village, Gunma, Japan, population 4573, 2230 males, 2343 females in 2017), local medical examinations are administered annually to screen for lifestyle-related diseases. The total number of participants in 2017 was 946. Of these, we recruited subjects who were $>40$ years old for a foot checkup by board-certified orthopedic surgeons, regardless of the presence of symptoms. Ultimately, 173 healthy volunteers participated in the checkup.

All of the individuals provided their written informed consent and responded to a baseline questionnaire, which asked for information, such as the age and gender. Of the 173 participants, a total of 169 (63 males, $106 \mathrm{fe-}$ males, average age: $66.0 \pm 12.4$ years old) who satisfied all of the examination criteria below were included in the present study, which was approved by our institutional review board. All procedures were performed according to the Declaration of Helsinki.

\section{Measurement of the photographic HV angle (pHVA)}

With a digital camera, we took photographs of the participants' feet in the standing position from a $15^{\circ}$ inclined angle relative to the vertical direction from a distance of $100 \mathrm{~cm}$ and then measured the pHVA (Fig. 1) $[14,15]$. First, we drew a tangential line from the inside edge of the hallux (A) to the inside edge of the head part of the first metatarsal bone (B). We then drew a line of the same length as $A B$ from point $B$ in the direction of the heel. Where the line came into contact with the inside edge of the first metatarsal bone was defined as

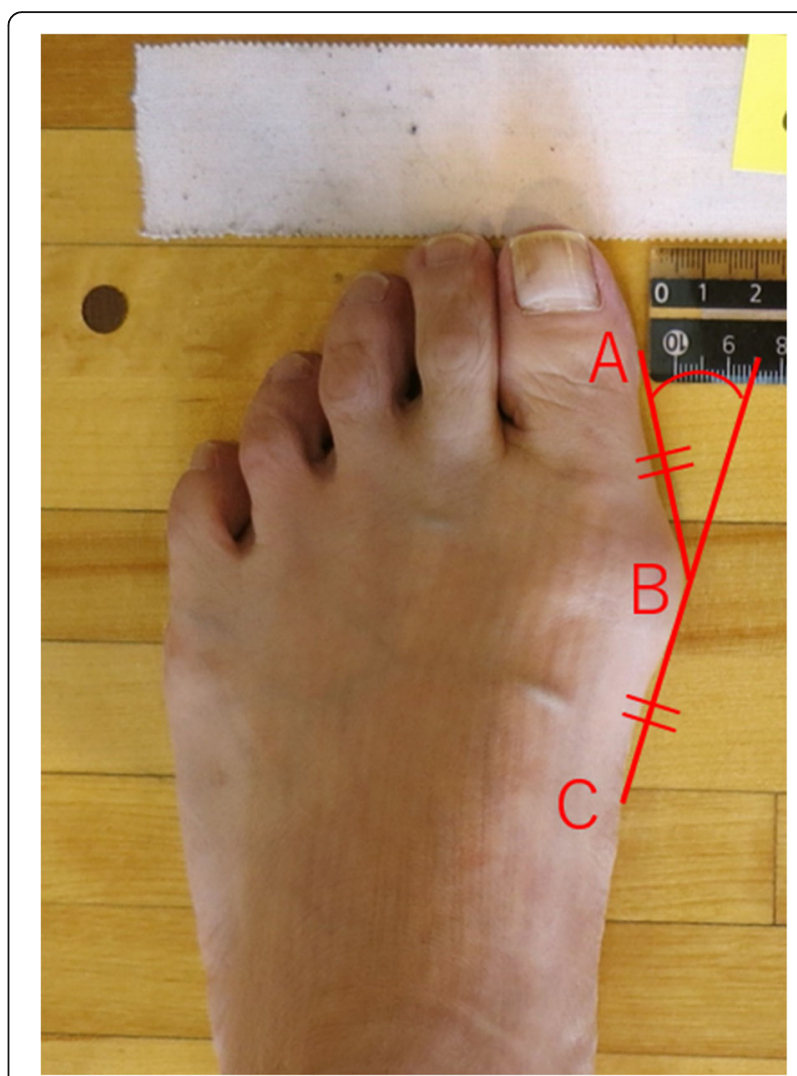

Fig. 1 Measurement of the photographic hallux valgus angle. A: The inside edge of the hallux. B: The inside edge of the head part of the first metatarsal bone. $\mathbf{C}$ : The inside edge of the part of the first metatarsal bone defined as the length of $A B=B C$. Photographic hallux valgus angle: The angle formed by $A B$ and $B C$

point C. Using an angle measurement application (hakarun ; onegland.net, Shizuoka, Japan), two examiners ( $\mathrm{HO}$ and $\mathrm{KT}$ ) measured the pHVA as the angle formed by $\mathrm{AB}$ and $\mathrm{BC}$.

A previous study reported that pHVA values were lower than the radiographic HV angle (rHVA) values, with a mean difference of $-5.3^{\circ}$ (95\% confidence interval [CI], -4.3 to -6.2$)$ [15]. HV is generally defined as an rHVA of $\geq 20^{\circ}$ [16]. In the present study, to prevent classifying participants with an $\mathrm{rHVA}<20^{\circ}$ into the $\mathrm{HV}$ group, we set the cut-off as a pHVA of $20^{\circ}$ and classified subjects into the HV group (pHVA of 1 or both feet $\geq$ $20^{\circ}$ ) and no HV group (pHVA of both feet $<20^{\circ}$ ). In addition, to analyze the relationship between the severity of $\mathrm{HV}$ and the magnitude of postural sway, we calculated the total pHVA for both feet.

\section{Hallux pain}

We asked participants about pain in their right and left hallux or first metatarsal joint while standing on both feet. We assessed the subjective pain of both feet using the Numerical Rating Scale (NRS) (0-10), in which a 
higher score indicates greater pain, and we further calculated the total NRS score for both feet.

\section{Postural sway}

Using a force plate (WIN POD ${ }^{\circ}$; medicapteurs, Balma, France), we assessed participants' static balance in standing position with 2-legged stance and eyes open $[5,17]$ (Fig. 2). We asked participants to stand on the force plate barefoot, with heels $10 \mathrm{~cm}$ apart, and to stare at a point $1.5 \mathrm{~m}$ away from the force plate for $30 \mathrm{~s}$. From a safety perspective, measurements in a single-leg stance or with the eyes closed were not conducted. We recorded the total trajectory length acquired by the measurement of the gravity center fluctuation $(\mathrm{mm})$, area of the center of pressure (COP; the area of an oval circumscribed to the gravity center fluctuation; $\mathrm{mm}^{2}$ ) and mediolateral and anteroposterior postural sway $(\mathrm{mm})$. The mediolateral axis of the center of gravity was defined as the $\mathrm{X}$-axis, and the anteroposterior axis of the center of gravity was defined as the Y-axis. The magnitude of the mediolateral and anteroposterior postural sway was expressed as the root-mean-square COP displacement, relative to the mean $(\mathrm{mm})$ [7].

\section{Measurement of the body muscle mass}

Using a bioelectrical impedance analysis (Tanita MC780 A multi frequency segmental body composition analyzer; Tanita Co., Ltd., Tokyo, Japan), we investigated the trunk and lower limb muscle mass $[18,19]$. The participants stepped onto the analyzer barefoot, each foot on 2 electrodes, and the examiner entered the participants' information (age, gender and height). Once the body mass was assessed by the scale, the participants held 2 electrodes gripped in each hand during impedance measurement, which was performed for $20 \mathrm{~s}$. Segmental muscle mass values were indicated on the digital screen (trunk, left and right lower limbs). We then calculated the total muscle mass of both lower limbs (lower limb muscle mass).

\section{Statistical analyses}

We assessed the intraclass correlation coefficients $\left(\mathrm{ICCs}_{1.1}\right)$ and interclass correlation coefficients $\left(\mathrm{ICCs}_{2.1}\right)$ for the procedure used to measure the pHVA. We performed univariate analyses using Welch's $t$-test and the chi-square test, and compared the $\mathrm{HV}$ and no $\mathrm{HV}$ groups. Using Spearman's correlation coefficient, we then analyzed the single correlation between the pHVA and magnitude of postural sway. After adjusting for potential confounders, we used a multiple linear regression model to further confirm the association between the presence of HV or pHVA and the magnitude of postural sway. A p-value of 0.05 was considered statistically significant. All statistical analyses were conducted using a statistical analysis system (IBM SPSS Statistics 26 software package; IBM Japan, Tokyo, Japan).

The sample size was calculated $(\alpha=0.05, \beta=0.2)$ before the present study. The minimum sample size was

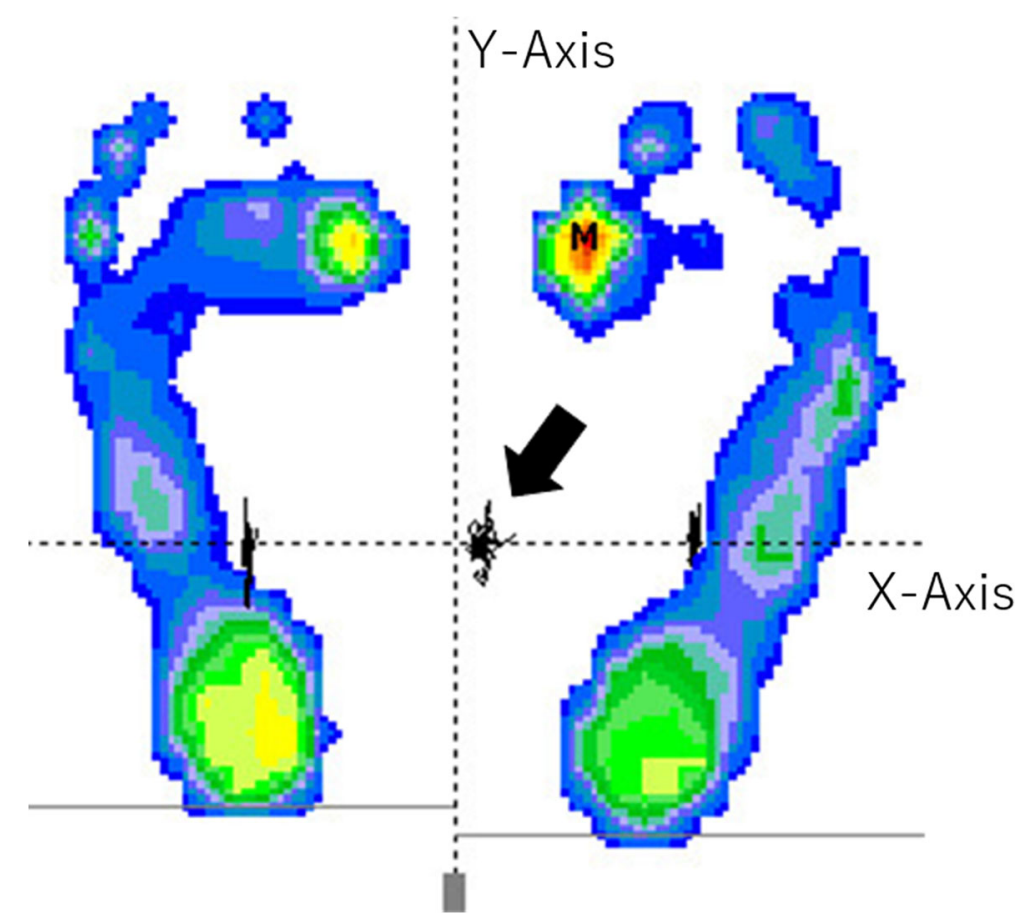

Fig. 2 Postural sway measured using a force plate. The trajectory of the center of gravity (black arrow) 
assessed using a statistical power analysis program (G*Power Version 3.1.; Universität Düsseldorf, Düsseldorf, Germany). The minimum sample size required for each group to achieve a statistical power of $>0.8$ was 33 in the HV group and 79 in the no HV group [2, 5].

\section{Results}

Regarding the measurement of the pHVA, the ICCs ${ }_{1.1}$ was 0.987 , and the $\mathrm{ICCs}_{2.1}$ was 0.983 . The HV group had 44 subjects ( 13 males, 31 females), whereas the no HV group had 125 subjects (50 males, 75 females). According to the univariate analysis, there were no significant differences between the HV and no HV groups with regard to the age, gender, or BMI. The anteroposterior postural sway in the HV group was significantly greater than that in the no HV group, whereas the difference in the mediolateral postural sway between the two groups was not significant. The lower limb muscle mass in the HV group was significantly smaller than that in the no HV group. There were no significant differences between the two groups with regard to the total NRS score for both feet, total trajectory length, area of COP, or trunk muscle mass (Table 1). In a multiple linear regression model, the magnitude of the anteroposterior postural sway was set as dependent variable. In addition to the presence of $\mathrm{HV}$, the age, gender and lower limb muscle mass were set as independent variables, since these variables were assumed to be potential

Table 1 Results of a univariate analysis of factors related to the presence of hallux valgus

\begin{tabular}{|c|c|c|c|}
\hline & $\begin{array}{l}\text { HV group } \\
(n=44)\end{array}$ & $\begin{array}{l}\text { No HV group } \\
(n=125)\end{array}$ & $p$-value \\
\hline Age (years) & $69.0 \pm 11.6$ & $65.7 \pm 11.6$ & $0.108^{a}$ \\
\hline \multicolumn{4}{|l|}{ Gender } \\
\hline Females & 31 & 75 & \\
\hline Males & 13 & 50 & $0.217^{b}$ \\
\hline $\mathrm{BMI}\left(\mathrm{kg} / \mathrm{m}^{2}\right)$ & $22.7 \pm 2.9$ & $23.7 \pm 3.0$ & $0.058^{\mathrm{a}}$ \\
\hline Total NRS score for both feet & $0.1 \pm 0.3$ & $0.4 \pm 2.0$ & $0.258^{\mathrm{a}}$ \\
\hline \multicolumn{4}{|l|}{ Postural sway } \\
\hline Total trajectory length $(\mathrm{mm})$ & $358.6 \pm 131.3$ & $328.6 \pm 205.5$ & $0.437^{\mathrm{a}}$ \\
\hline Area of COP $\left(\mathrm{mm}^{2}\right)$ & $303.9 \pm 195.8$ & $238.7 \pm 178.1$ & $0.056^{\mathrm{a}}$ \\
\hline $\begin{array}{l}\text { The mediolateral postural } \\
\text { sway }(\mathrm{mm})\end{array}$ & $4.5 \pm 2.0$ & $3.9 \pm 1.9$ & $0.090^{\mathrm{a}}$ \\
\hline $\begin{array}{l}\text { The anteroposterior } \\
\text { postural sway }(\mathrm{mm})\end{array}$ & $6.5 \pm 2.8$ & $5.4 \pm 2.2$ & $0.014^{*} a$ \\
\hline \multicolumn{4}{|l|}{ Body muscle mass (kg) } \\
\hline Trunk & $22.6 \pm 3.8$ & $22.3 \pm 3.5$ & $0.620^{\mathrm{a}}$ \\
\hline Lower limbs & $12.4 \pm 2.2$ & $13.5 \pm 3.2$ & $0.016^{*} a$ \\
\hline
\end{tabular}

The values are given as the mean and standard deviation

$H V$ hallux valgus, $B M I$ body mass index, COP center of pressure, NRS numerical rating scale

${ }^{\mathrm{a} W e l c h}$ 's test, ${ }^{\mathrm{b}} \mathrm{Chi}$-square test, ${ }^{*} p<0.05$ confounders. In this model, only the presence of HV was significantly related to the magnitude of the anteroposterior postural sway (Table 2).

The Spearman's correlation analysis showed that the total value of pHVA on both feet was positively correlated with the anteroposterior postural sway and negatively correlated with the lower limb muscle mass (Fig. 3; Table 3). In a multiple linear regression model with the anteroposterior postural sway as the dependent variable and the total value of the pHVA on both feet, age, gender and lower limb muscle mass as independent variables, only the total pHVA for both feet was independently correlated with the magnitude of the anteroposterior postural sway (Table 4).

\section{Discussion}

The present study demonstrated two main findings. First, the presence of $\mathrm{HV}$ was independently related to the magnitude of the anteroposterior postural sway. Second, the severity of HV deformity was also related to the magnitude of the anteroposterior postural sway.

Previous studies have shown that $\mathrm{HV}$ is inversely related to the hallux plantar load pressure $[8,20]$, hallux plantarflexion strength [5] and tactile sensation or proprioception [21], all of which are important for preventing postural sway while the gravity center moves to the anterior part of the foot. These reasons may explain the potential relationship between HV deformity and postural sway in the anteroposterior direction. In line with our findings, a study also reported that the presence of HV was significantly related to the postural sway, although the sway was found in the mediolateral direction [6]. In that previous study, the subjects were $>20$ years old, $\mathrm{HV}$ was defined as an rHVA $>15^{\circ}$ on radiographs, and the measurement time was $70 \mathrm{~s}$. Thus, such subjects and basic procedures in the previous study might have resulted in the direction of postural sway differing from the present findings.

Several researchers reported that HV was an important risk factor for falls [22-24]. In addition, a study found

Table 2 Regression analysis findings of the factors associated with the magnitude of the anteroposterior postural sway

\begin{tabular}{lll}
\hline & $\begin{array}{l}\text { Standardized partial } \\
\text { regression coefficient } \boldsymbol{\beta}\end{array}$ & $\boldsymbol{p}$-value \\
\hline Age (years) & 0.128 & 0.196 \\
Gender & 0.092 & 0.463 \\
The presence of HV & 0.176 & $0.024^{*}$ \\
The lower limb muscle mass (kg) & 0.073 & 0.584 \\
\hline
\end{tabular}

The dependent variable was the magnitude of the anteroposterior postural sway. The independent variables were the age, gender, presence of HV and lower limb muscle mass

$H V$ hallux valgus

${ }^{*} p<0.05$ 


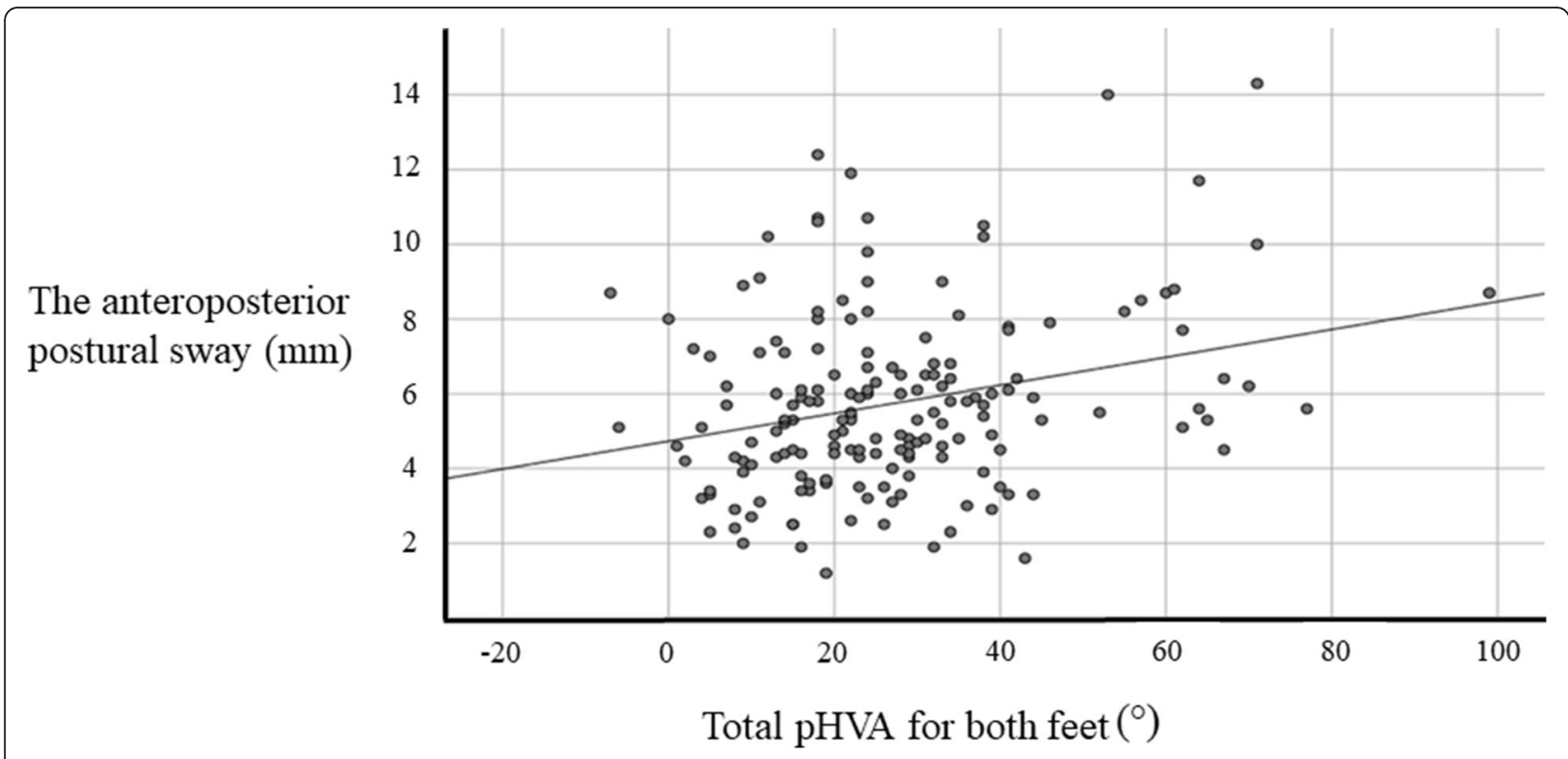

Fig. 3 Correlation between the severity of hallux valgus and the anteroposterior postural sway. The total value of the photographic hallux valgus angle for both feet was positively correlated with the anteroposterior postural sway

that, in the standing position with a 2-legged stance and eyes open, fallers tended to have a greater anteroposterior postural sway (an increase of $25 \%$ ) than non-fallers [7]. In line with that study, we found that the anteroposterior postural sway in the HV group was increased by $20 \%$ compared to that in the no HV group. Although further studies are needed, based on the present as well as previous reports, falls in subjects with HV may be related to the anteroposterior postural sway. Furthermore, HV deformity can progress over time [25], and the severity of $\mathrm{HV}$ was correlated with the magnitude of the postural sway in the present study. Thus, it may be important to monitor the progress of a patient's HV deformity.

Several limitations associated with the present study warrant mention. First, we did not investigate the history

Table 3 Correlations between the severity of hallux valgus and measured variables

\begin{tabular}{lll}
\hline & \multicolumn{2}{l}{ Total pHVA for both feet $\left(^{\circ}\right)$} \\
\cline { 2 - 3 } & $\boldsymbol{r}$ & $\boldsymbol{P}$ \\
\hline Age (years) & 0.120 & 0.119 \\
BMI $\left(\mathrm{kg} / \mathrm{m}^{2}\right)$ & -0.128 & 0.096 \\
The anteroposterior postural sway $(\mathrm{mm})$ & $0.177^{*}$ & 0.021 \\
The lower limb muscle mass $(\mathrm{kg})$ & $-0.160^{*}$ & 0.038
\end{tabular}

Data are shown as Spearman's correlation coefficient $(r)$

$B M I$ body mass index, NRS numerical rating scale, $p H V A$ photographic hallux valgus angle

${ }^{*} p<0.05$ of fall in this study. Therefore, we could not conclude that increased postural sway was directly related to fall. Second, measurements in a single-leg stance and eyes closed were not conducted from the perspective of safety. Finally, ocular disease might have affected the subjects' ability to stare at a point $1.5 \mathrm{~m}$ from the force plate during the measurement of postural sway. Despite these limitations, a strength of the present study is that we clarified for the first time the association of the presence and severity of HV deformity and the anteroposterior postural sway among healthy volunteers.

\section{Conclusions}

The presence and severity of HV deformity were independent factors related to the anteroposterior postural sway in a standing position with a 2-legged stance and eyes open.

Table 4 Regression analysis findings of the factors associated with the magnitude of the anteroposterior postural sway

\begin{tabular}{lll}
\hline & $\begin{array}{l}\text { Standardized partial } \\
\text { regression coefficient } \boldsymbol{\beta}\end{array}$ & p-value \\
\hline Age (years) & 0.102 & 0.335 \\
Gender & 0.044 & 0.757 \\
Total pHVA for both feet $\left(^{\circ}\right)$ & 0.214 & $0.008^{*}$ \\
The lower limb muscle mass $(\mathrm{kg})$ & 0.033 & 0.837 \\
\hline
\end{tabular}

The dependent variable was the magnitude of the anteroposterior postural sway. The independent variables were the age, gender, total value of pHVA and lower limb muscle mass

pHVA photographic hallux valgus angle ${ }^{*} p<0.05$ 


\section{Abbreviations}

BMl: Body mass index; COP: Center of pressure; HV: Hallux valgus; ICC: Intraclass correlation coefficients; NRS: Numerical rating scale; pHVA: Photographic hallux valgus angle

\section{Acknowledgements}

The authors thank the participants and medical staff and public health nurses of the regional health center for their assistance and support in this study.

\section{Authors' contributions}

$\mathrm{HO}$ is responsible for the study design, data collections, analyses and writing $\mathrm{TO}$ (1), NH, TO (2), SH and $\mathrm{AU}$ are responsible for the study design. $\mathrm{KT}$ is responsible for the data collection and analyses. $\mathrm{TT}, \mathrm{YI}$ and $\mathrm{HC}$ are responsible for the manuscript preparation. The authors read and approved the final manuscript.

\section{Funding}

This research did not receive any specific grant from funding agencies in the public, commercial or not-for-profit sectors.

\section{Availability of data and materials}

The data are available from the corresponding author upon reasonable request.

\section{Declarations}

\section{Ethics approval and consent to participate}

This study was approved by the institutional review board of Gunma University Hospital (2017 - 135). Written informed consent was obtained from all participants. All procedures were performed according to the Declaration of Helsinki.

\section{Consent for publication}

Not applicable.

\section{Competing interests}

None of the authors has a conflict of interest that could inappropriately influence this work.

\section{Author details}

'Department of Orthopaedic Surgery, Gunma University Graduate School of Medicine, 3-39-22, Showa, Gunma 371-8511 Maebashi, Japan. ${ }^{2}$ East Maebashi Orthopaedic Hospital Center of Foot and Ankle Surgery, 1302-2, Nishiomuro, Gunma 379-2104 Maebashi, Japan. 3 Department of Orthopaedic Surgery, Kiryu Orthopaedic Hospital, 284-1, Ainoshima, Hirosawa-machi, Gunma 376-0014 Kiryu, Japan

\section{Received: 9 February 2021 Accepted: 29 April 2021}

Published online: 31 May 2021

\section{References}

1. Nix S, Smith M, Vicenzino B. Prevalence of hallux valgus in the general population: a systematic review and meta-analysis. J Foot Ankle Res. 2010;3:21.

2. Nishimura A, Fukuda A, Nakazora S, Uchida A, Sudo A, Kato K, Yamada T. Prevalence of hallux valgus and risk factors among Japanese community dwellers. J Orthop Sci. 2014:19(2):257-62.

3. Roddy E, Zhang W, Doherty M. Prevalence and associations of hallux valgus in a primary care population. Arthritis Rheum. 2008;59(6):857-62.

4. Menz HB, Morris ME, Lord SR. Foot and ankle characteristics associated with impaired balance and functional ability in older people. J Gerontol A Biol Sci Med Sci. 2005:60(12):1546-52.

5. Nix SE, Vicenzino BT, Smith MD. Foot pain and functional limitation in healthy adults with hallux valgus: a cross-sectional study. BMC Musculoskelet Disord. 2012;13:197.

6. Spink MJ, Fotoohabadi MR, Wee E, Hill KD, Lord SR, Menz HB. Foot and ankle strength, range of motion, posture, and deformity are associated with balance and functional ability in older adults. Arch Phys Med Rehabil. 2011; 92(1):68-75
7. Maki BE, Holliday PJ, Topper AK. A prospective study of postural balance and risk of falling in an ambulatory and independent elderly population. $J$ Gerontol. 1994;49(2):M72-84.

8. Nishimura A, Ito N, Nakazora S, Kato K, Ogura T, Sudo A. Does hallux valgus impair physical function? BMC Musculoskelet Disord. 2018;19(1):174.

9. Maclennan R. Prevalence of hallux valgus in a neolithic New Guinea population. Lancet. 1966;1 (7452):1398-400.

10. Kasai T, Ishiguro N, Matsui Y, Harada A, Takemura M, Yuki A, Kato Y, Otsuka $\mathrm{R}$, Ando F, Shimokata $\mathrm{H}$. Sex- and age-related differences in mid-thigh composition and muscle quality determined by computed tomography in middle-aged and elderly Japanese. Geriatr Gerontol Int. 2015:15(6):700-6.

11. He X, Li Z, Tang X, Zhang L, Wang L, He Y, Jin T, Yuan D. Age- and sexrelated differences in body composition in healthy subjects aged 18 to 82 years. Medicine (Baltimore). 2018;97(25):e11152.

12. Shahtahmassebi $B$, Hebert JJ, Hecimovich M, Fairchild TJ. Trunk exercise training improves muscle size, strength, and function in older adults: A randomized controlled trial. Scand J Med Sci Sports. 2019:29(7):980-91.

13. Chakravarty K, Chatterjee D, Das RK, Tripathy SR, Sinha A. Analysis of muscle activation in lower extremity for static balance. Conf Proc IEEE Eng Med Biol Soc. 2017:2017:4118-22

14. Nix S, Russell T, Vicenzino B, Smith M. Validity and reliability of hallux valgus angle measured on digital photographs. J Orthop Sports Phys Ther. 2012; 42(7):642-8

15. Yamaguchi $S$, Sadamasu A, Kimura S, Akagi R, Yamamoto $Y$, Sato $Y$, Sasho T, Ohtori S. Nonradiographic Measurement of Hallux Valgus Angle Using Selfphotography. J Orthop Sports Phys Ther. 2019:49(2):80-86.

16. Hurn SE, Vicenzino B, Smith MD. Functional impairments characterizing mild, moderate, and severe hallux valgus. Arthritis Care Res (Hoboken). 2015;67(1):80-8.

17. Meiners KM, Loudon JK. Dynamic and Static Assessment of Single-Leg Postural Control in Female Soccer Players. J Sport Rehabil. 2020;29(2):174-8.

18. Janssen I, Heymsfield SB, Baumgartner RN, Ross R. Estimation of skeletal muscle mass by bioelectrical impedance analysis. J Appl Physiol (1985). 2000;89(2):465-71.

19. Thivel D, Verney J, Miguet M, Masurier J, Cardenoux C, Lambert C, Courteix $D$, Metz $L$, Pereira B. The accuracy of bioelectrical impedance to track body composition changes depends on the degree of obesity in adolescents with obesity. Nutr Res. 2018;54:60-8.

20. Galica AM, Hagedorn TJ, Dufour AB, Riskowski JL, Hillstrom HJ, Casey VA Hannan MT. Hallux valgus and plantar pressure loading: the Framingham foot study. J Foot Ankle Res. 2013;6(1):42.

21. Sadra S, Fleischer A, Klein E, Grewal GS, Knight J, Weil LS, Weil L, Najafi B. Hallux valgus surgery may produce early improvements in balance control: results of a cross-sectional pilot study. J Am Podiatr Med Assoc. 2013;103(6): 489-97.

22. Menz HB, Morris ME, Lord SR. Foot and ankle risk factors for falls in older people: a prospective study. J Gerontol A Biol Sci Med Sci. 2006;61(8):866-70.

23. Mickle KJ, Munro BJ, Lord SR, Menz HB, Steele JR. ISB Clinical Biomechanics Award 2009: toe weakness and deformity increase the risk of falls in older people. Clin Biomech (Bristol, Avon). 2009;24(10):787-91.

24. Koski K, Luukinen H, Laippala P, Kivela SL. Physiological factors and medications as predictors of injurious falls by elderly people: a prospective population-based study. Age Ageing. 1996;25(1):29-38.

25. Koo KK, Tse LF, Cheng HS, Ho KKW. The progression of hallux valgus in the oriental Chinese population in Hong Kong. Foot (Edinb). 2017:32:15-21.

\section{Publisher's Note}

Springer Nature remains neutral with regard to jurisdictional claims in published maps and institutional affiliations. 